\title{
Identifying the lowest effective dose of acetazolamide for the prophylaxis of acute mountain sickness: systematic review and meta-analysis
}

\author{
(?) $(\Theta)$ OPEN ACCESS
}

\author{
Emma V Low medical student ${ }^{1}$, Anthony J Avery professor ${ }^{2}$, Vaibhav Gupta medical student ${ }^{2}$, \\ Angela Schedlbauer clinical lecturer ${ }^{3}$, Michael P W Grocott professor ${ }^{4}$
}

\begin{abstract}
${ }^{1}$ School of Medicine, University of Southampton, Southampton General Hospital, Southampton, UK; ${ }^{2}$ Division of Primary Care, School of Community Health Sciences, The Medical School , University of Nottingham, Queen's Medical Centre, Nottingham NG7 2UH, UK; ${ }^{3}$ Division of Primary Care, School of Community Health Sciences, Tower Building, University of Nottingham, UK; ${ }^{4}$ Anaesthesia and Critical Care Research Unit, University Hospital Southampton NHS Foundation Trust, Southampton, UK
\end{abstract}

\begin{abstract}
Objectives To assess the efficacy of three different daily doses of acetazolamide in the prevention of acute mountain sickness and to determine the lowest effective dose.

Design Systematic review and meta-analysis.

Data sources Medline and Embase along with a hand search of selected bibliographies. No language restrictions were applied.

Study selection Randomised controlled trials assessing the use of acetazolamide at $250 \mathrm{mg}, 500 \mathrm{mg}$, or $750 \mathrm{mg}$ daily versus placebo in adults as a drug intervention for the prophylaxis of acute mountain sickness. Included studies were required to state the administered dose of acetazolamide and to randomise participants before ascent to either acetazolamide or placebo. Two reviewers independently carried out the selection process.
\end{abstract}

Data extraction Two reviewers extracted data concerning study methods, pharmacological intervention with acetazolamide, method of assessment of acute mountain sickness, and event rates in both control and intervention groups, which were verified and analysed by the review team collaboratively.

Data synthesis 11 studies (with 12 interventions arms) were included in the review. Acetazolamide at doses of $250 \mathrm{mg}, 500 \mathrm{mg}$, and $750 \mathrm{mg}$ were all effective in preventing acute mountain sickness above $3000 \mathrm{~m}$, with a combined odds ratio of 0.36 (95\% confidence interval 0.28 to 0.46). At a dose of $250 \mathrm{mg}$ daily the number needed to treat for acetazolamide to prevent acute mountain sickness was $6(95 \%$ confidence interval 5 to 11$)$. Heterogeneity ranged from $\mathrm{I}^{2}=0 \%(500 \mathrm{mg}$ subgroup) to $\mathrm{I}^{2}=44 \%$ (750 mg subgroup).

Conclusions Acetazolamide in doses of $250 \mathrm{mg}, 500 \mathrm{mg}$, and $750 \mathrm{mg}$ daily are all more effective than placebo for preventing acute mountain sickness. Acetazolamide $250 \mathrm{mg}$ daily is the lowest effective dose to prevent acute mountain sickness for which evidence is available.

\section{Introduction}

Treks at high altitude are becoming increasingly accessible to and popular with the general population. Between 1990 and 2009, 26273 people attempted to climb the highest peaks in the Nepalese Himalayas, at altitudes of 6000-8850 m, ${ }^{1}$ and each year over 20000 people attempt to climb Mount Kilimanjaro in Tanzania. ${ }^{2}$ With the ever increasing number of people ascending to high altitudes, medicines to deal with potential problems are becoming increasingly relevant to non-specialists, including general practitioners. A clinical review published in $2011^{3}$ highlighted the need for clinicians to provide well informed advice to climbers on the prevention and management of high altitude illness. For clinicians to remain well informed, relevant and up to date information must be clear and easily accessible.

Acute mountain sickness and high altitude headache are commonly encountered at altitude. Acute mountain sickness can lead to high altitude pulmonary oedema and high altitude cerebral oedema; potentially life threatening illnesses. A spectrum of symptoms related to acute mountain sickness may 
develop at altitudes below $3000 \mathrm{~m}$ : commonly reported symptoms are nausea, vomiting, headache, dizziness, fatigue, and sleep disturbance. ${ }^{4}$ Although slow ascent to altitude remains the most important measure to prevent acute mountain sickness, evidence from the literature on high altitude suggests that drugs can complement gradual ascent in preventing acute mountain sickness. ${ }^{5}$ Treatment typically occurs on the mountainside, but seeking to prevent acute mountain sickness begins before the ascent to high altitude (generally $>3000 \mathrm{~m}$ ).

The carbonic anhydrase inhibitor acetazolamide is now widely accepted as the standard drug for the prophylaxis of acute mountain sickness, ${ }^{46}$ despite not being licensed for this purpose. ${ }^{7}$ Alternative interventions for this indication include gingko biloba, dexamethasone, and antioxidant vitamin supplements, although these agents are beyond the scope of this review. ${ }^{8-10}$ Acetazolamide promotes acclimatisation to altitude; it acts to increase bicarbonate secretion by the kidneys, induce metabolic acidosis, and stimulate ventilation. ${ }^{41}$ Much debate surrounds the effective dose for prevention of acute mountain sickness. ${ }^{6}$ A systematic review published in $2000^{12}$ found that $750 \mathrm{mg}$ was the lowest effective dose for preventing acute mountain sickness. This suggestion has been disputed by mountaineering specialists in both the general medical literature ${ }^{13} 14$ and the literature on high altitude. ${ }^{515}$ This has left clinicians, especially those without a thorough knowledge of the current literature, with the clinical dilemma of what dose of acetazolamide to prescribe to prevent acute mountain sickness in people ascending to high altitude.

We carried out a systematic review to assess the efficacy of three different doses of acetazolamide-250 mg, $500 \mathrm{mg}$, and $750 \mathrm{mg}$ - in the prevention of acute mountain sickness at high altitude and to determine the lowest effective dose.

Acetazolamide $250 \mathrm{mg}$ daily is the lowest dose assessed by this review because of the lack of data on lower doses.

\section{Methods}

We considered studies for inclusion if they assessed the use of acetazolamide versus placebo as a drug intervention for the prophylaxis of acute mountain sickness. Studies were required to state the administered dose of acetazolamide and to randomise participants before ascent to either acetazolamide or placebo.

We included randomised controlled trials, of healthy participants aged more than 16 years. Participants had to have ascended to high altitude, which for the purpose of this review we defined as more than $3000 \mathrm{~m}$. We excluded studies that recruited participants from indigenous or local populations because of the possibility of inherited or acquired physiological adaptation to altitude.

\section{Outcome measures}

The primary outcome was absence of acute mountain sickness. The Lake Louise scoring system can be used to diagnose acute mountain sickness and to assess the severity of symptoms. This scoring system was developed by a panel of experts at the 1991 International Hypoxia Symposium and is widely accepted as the standard tool for diagnosing acute mountain sickness. ${ }^{3}$

According to the Lake Louise consensus criteria, acute mountain sickness is defined as the presence of headache with at least one other symptom after recent ascent to altitude: gastrointestinal disturbance (anorexia, nausea, vomiting), dizziness, light headedness, insomnia, or fatigue. A score of more than 3 is consistent with a diagnosis of acute mountain sickness. ${ }^{16}$ Where studies did not use the Lake Louise scoring system, we chose the primary end point to be the absence of acute mountain sickness, defined using a validated symptom scoring system such as the general high altitude questionnaire, the acute mountain sickness-cerebral score, or a clear definition of acute mountain sickness predetermined by the original study authors. After we had accessed the full text and reviewed the data, we excluded studies if a clear definition of acute mountain sickness was not stated or if the incidence of acute mountain sickness was unclear among the study population.

\section{Literature search}

We searched Medline (inception to 22 January 2012) and Embase (inception to 22 January 2012) using a sensitive search strategy to identify eligible randomised controlled trials. Search terms were "Randomi* controlled trial.pt." OR "Randomi*.ab." OR “Controlled clinical trial.pt." OR "Placebo.ab.” OR "Drug therapy.fs.” OR "Randomly.ab.” OR “Trial.ab.” OR

"Groups.ab.” AND “Altitude" OR "Mountain sickness". We also hand searched journals on high altitude medicine (January 1975 to 2 August 2011): Aviation, Space and Environmental Medicine; High Altitude Medicine and Biology; and Wilderness and Environmental Medicine.

Bibliographies belonging to included papers, known reviews, and relevant articles were searched for additional trials. To identify additional unpublished studies we corresponded with the primary author from each of the included studies and several of the excluded studies.

\section{Study selection and evaluation}

Two investigators (EVL, VG) identified suitable trials from the database search and independently reviewed the title and abstracts of articles. Studies were excluded if they concerned non-humans, children, or focused on participant populations with underlying medical conditions (for example, diabetes mellitus) or with a history of acute mountain sickness or altitude related illness (for example, high altitude cerebral oedema or high altitude pulmonary oedema). Studies were excluded if they were non-randomised controlled trials, or were non-controlled clinical trials. We excluded trials where the content was unrelated to the current research topic, that did not primarily assess prevention of acute mountain sickness, where the final altitude specified was below $3000 \mathrm{~m}$, or where ascent to altitude was simulated in a hypobaric chamber. Finally we excluded studies with indigenous or local populations as trial participants. No language restrictions were applied to the selection process. We used a hierarchical template to classify the excluded studies. The remaining papers were reviewed in full and assessed using a predetermined set of inclusion criteria. Disagreements were resolved by discussion among the review team.

\section{Data extraction}

The lead reviewer designed and used a template for extraction of relevant data from the included studies. A second reviewer verified the extracted data. Discrepancies were discussed and resolved after consultation with the review team. Where necessary, study authors were contacted for unpublished data.

\section{Risk of bias}

Two reviewers (EVL, AS) independently evaluated the quality of the included trials by using the Cochrane Collaboration's tool for assessing risk of bias. ${ }^{17}$ Each study was assessed for random sequence generation, allocation concealment, blinding of participants, blinding of outcome assessment, incomplete outcome data, selective reporting, and other sources of bias. 


\section{Statistical analysis}

We tested dichotomous data for heterogeneity and applied fixed or random effects models in the statistical analysis. The results are reported in a forest plot with $95 \%$ confidence intervals. The odds ratio represents the measure of relative effect of the intervention and is calculated for each subgroup. An odds ratio of less than 1 favours the intervention for preventing an acute mountain sickness event among participants. For the purpose of the meta-analysis where studies compared two drug intervention arms with a shared control group, we divided the control group in to two. This allowed direct analysis of the event rate in each intervention arm with a control group, avoiding replication of the control group and subsequent unit of analysis error. ${ }^{17}$ We used the Cochrane calculator to determine the number needed to treat to prevent one event of acute mountain sickness.

Statistical heterogeneity was assessed both visually and by using the $\chi^{2}$ test. Heterogeneity of the intervention effect was quantified between studies using the $\mathrm{I}^{2}$ statistic. ${ }^{18}{ }^{19}$ When interpreting heterogeneity, $\mathrm{I}^{2}$ values less than $30 \%$ are considered as low heterogeneity, less than $60 \%$ as moderate, and greater than $60 \%$ as high. ${ }^{18}$ We carried out subgroup analysis to investigate possible causes of clinical heterogeneity, looking at variability between the interventions, participants, and outcomes across the studies. To identify methodological heterogeneity we also assessed study design and risk of bias.

\section{Results}

The literature search yielded 3133 articles from Medline and Embase (fig $1 \Downarrow$ ). Hand searches of the bibliographies identified two additional studies. ${ }^{2021}$ After removing duplicates, 3048 studies were reviewed against the prespecified exclusion criteria of which 3005 were excluded on the basis of the titles and abstracts. Of 43 full text articles retrieved and reviewed 32 did not meet the predefined inclusion criteria and were excluded (see supplementary table). The two studies identified from a hand search of bibliographies were excluded because one was not a randomised controlled trial and the outcome criteria were not clearly reported, ${ }^{20}$ and the other did not clearly report the incidence of acute mountain sickness among the study participants. ${ }^{21}$ Eleven papers (with 12 intervention arms) were included for meta-analysis. Table $1 \Downarrow$ shows the characteristics of the included studies.

\section{Included studies}

Publication dates of the 11 studies included in the meta-analysis ranged from 1976 to 2011. Eight of the included studies were published after the original review by Dumont. ${ }^{513} 15$ 23-27 Trials were carried out worldwide, with seven of the 11 trials taking place on Mount Everest, ${ }^{5} 131522232527$ three in the United States, ${ }^{24} 2628$ and one in Pakistan. ${ }^{29}$ All the trials included both men and women. The mean number of participants per trial was 137 (range 12-339). The mean number of participants in the control groups was 61 (range 6-165) and in the intervention groups was 76 (6-174). The median altitude at which study participants were enrolled was $3440 \mathrm{~m}$ (range sea level to 4358 $\mathrm{m}$ ). The mean final altitude was $4619 \mathrm{~m}$ (range 3800-5000 m).

All the studies compared the effectiveness of acetazolamide with placebo in preventing acute mountain sickness. In 10 of the 11 trials $^{5}{ }_{13}^{23-30}$ the intervention group received a specific dose of acetazolamide and was compared directly with a placebo group. In one trial two intervention groups (acetazolamide 250 $\mathrm{mg}$ and acetazolamide $750 \mathrm{mg}$ ) were compared with a shared placebo group. ${ }^{15}$ For the meta-analysis, the control group was split in to two to allow direct calculation of the odds ratio, avoiding a unit of analysis error. ${ }^{17}$ The control group originally made up of 59 participants was split to give 29 participants in the $250 \mathrm{mg}$ control group and 30 in the $750 \mathrm{mg}$ control group. This avoided replication of the control group in the overall analysis. The total daily dose of acetazolamide in the intervention groups varied between the trials; four used $250 \mathrm{mg}$ of acetazolamide for the intervention group, ${ }^{5}{ }^{1525} 26$ six used 500 $\mathrm{mg},{ }^{1323-25} 2729$ and two used $750 \mathrm{mg} .{ }^{1528}$

The first dose was administered on the day of ascent in five trials $^{515222327}$ and a day or more before ascent in six. ${ }^{13} 25-272829$

Eight of the 11 studies used the Lake Louise scoring system and Lake Louise questionnaire for diagnosis. ${ }^{5}{ }^{1523-27}$ The remaining studies used the general high altitude questionnaire, ${ }^{28}$ acute mountain sickness-cerebral scores ${ }^{26}$ and individual symptom scoring systems. ${ }^{27} 29$

\section{Risk of bias}

Table $2 \Downarrow$ presents the results of the risk of bias assessment for the included studies. Random sequence generation was assessed as adequate in eight of the 11 trials and for these studies selection bias was judged as being a low risk. Three studies used a computer generated randomisation code for allocation of intervention. ${ }^{13}{ }^{22}{ }^{25}$ Other methods of random sequence generation included non-computer generated randomisation codes, random numbers tables, and on-site methods of randomised distribution. Ten of the 11 trials were assessed as adequate for allocation concealment. One study did not provide adequate information to make a judgment about allocation concealment. $^{29}$

Blinding of participants and staff was adequately reported in six of the 11 studies. Four studies ${ }^{1326-28}$ did not provide adequate information to formulate a judgment on performance bias (unclear risk). One study was judged to be at high risk of performance bias. $^{28}$

The different methods used to diagnose acute mountain sickness are a threat to consistency of outcomes between studies and are likely to introduce detection bias. The application of a standardised system of diagnosing acute mountain sickness was therefore an important criterion for the inclusion of studies, with most studies ${ }^{5131522} 2325$ applying the Lake Louise scoring system, based on assessment of symptoms such as gastrointestinal disturbance (anorexia, nausea, vomiting), dizziness, light headedness, insomnia, or fatigue. The scoring systems used by three other studies were all based on assessment of similar symptoms, deemed to result in a comparable level of outcome reporting. ${ }^{27-29}$ One study used a combination of assessment criteria (Lake Louise scoring system and acute mountain sickness-cerebral score) and showed a reduction in the incidence of acute mountain sickness and severity regardless of the method of outcome assessment applied, suggesting a positive correlation between the different methods. ${ }^{26}$

Reporting of blinding of outcome assessment was inconsistently reported among included studies. Eight studies provided inadequate information to make a judgment on blinding of outcome assessment. Three studies clearly stated that outcome assessment was blinded. ${ }^{5} 1524$

Five of the 11 studies $^{5} 15252728$ were assessed as having a high risk of attrition bias owing to incomplete outcome data. These studies reported a high proportion of participants who were lost to follow-up. Participants who encountered adverse events may have descended before outcome assessment. It is possible that the intervention effect was overestimated in these studies. The 
remaining six studies discussed withdrawals and exclusions and were judged as having a low risk of attrition bias..$^{1323-26} 29$

Two studies were judged as having a low risk of reporting bias. ${ }^{57}$ Eight of the 11 trials provided inadequate information to make a judgment about selective reporting. Often the study protocol was unavailable for review to determine whether prespecified outcomes were reported in the trial analysis. One study was deemed as being at high risk of selective reporting. ${ }^{29}$ Unpublished data were obtained from the original author ( $\mathrm{N} \mathrm{K}$ Burki, personal communication, 2011) of this trial to determine from the raw data the incidence of acute mountain sickness among participants. The criteria used by study authors to diagnose acute mountain sickness were not published in the original study.

Ascent profiles and timing of the delivery of acetazolamide were not consistently reported among the trials. Publication bias was assessed by funnel plot (see supplementary fig 4).

\section{Event rate in control groups}

The proportion of participants who developed acute mountain sickness in the 12 control groups combined (the mean control event rate) represent the underlying risk of acute mountain sickness in the study population. The combined mean control event rate was $33 \%$ in all trials ( 227 out of 680 controls), ranging from $20 \%$ (13/64) to $83 \%(5 / 6)$. Trials using $750 \mathrm{mg}$ daily, the highest dose of acetazolamide, had a higher underlying risk of acute mountain sickness $(56 \%, 34 / 60)$ compared with trials using $500 \mathrm{mg}(30 \%, 125 / 423)$ and $250 \mathrm{mg}$ (35\%, 68/197). The control event rates for the two studies included in the $750 \mathrm{mg}$ subgroup were $47 \%{ }^{15}$ and $67 \% .^{28}$

The proportion of participants who developed acute mountain sickness in the intervention groups (the mean experimental event rate) was $22 \%$, ranging from $10 \%$ (18/174) to $50 \%$ (3/6). Table $3 \Downarrow$ provides the data for efficacy of acetazolamide by dose.

Among the four studies that reported the incidence of high altitude pulmonary oedema and high altitude cerebral oedema as an outcome measure, only one case of high altitude cerebral oedema was identified in the placebo arm of a study ( 1 per 20 participants). ${ }^{24}$ No deaths were reported among study participants in control or intervention groups.

\section{Quantitative analysis of intervention effect Overall treatment effect}

The direction of intervention effect for the primary outcome was consistent for all studies; intervention with acetazolamide was consistently more effective than placebo for prevention of acute mountain sickness. The overall effect estimate for all subgroups combined indicated a statistically significant treatment effect of acetazolamide versus placebo, with a combined odds ratio of 0.36 (95\% confidence interval 0.28 to $0.46)$.

\section{Acetazolamide $250 \mathrm{mg}$ versus placebo}

The point estimates of the four studies (448 participants) that compared acetazolamide $250 \mathrm{mg}$ with placebo ${ }^{5152526}$ indicated a beneficial effect of acetazolamide (fig $2 \Downarrow$ ). Of these studies, only one showed a significant reduction in the risk of acute mountain sickness associated with acetazolamide $250 \mathrm{mg}$ (odds ratio $0.14,95 \%$ confidence interval 0.04 to 0.52$){ }^{26}$ The results of the remaining studies were not significant at the $5 \%$ significance level. ${ }^{51525}$ The combined estimate indicated a statistically significant treatment effect of acetazolamide 250 mg daily, with a combined odds ratio of 0.41 (0.26 to 0.64$)$.

\section{Acetazolamide $500 \mathrm{mg}$ versus placebo}

Six studies (907 participants) compared acetazolamide $500 \mathrm{mg}$ with placebo. Two studies showed a significant reduction in the risk of acute mountain sickness associated with acetazolamide $500 \mathrm{mg}$, with odds ratios of 0.41 (0.22 to 0.76$),{ }^{22}$ and 0.27 (0.14 to 0.52$).{ }^{13}$ The four remaining studies indicated reductions in the risk of acute mountain sickness, with odds ratios of 0.46 (0.19 to 1.13$),{ }^{23} 0.20$ (0.01 to 2.91$),{ }^{29} 0.29$ (0.08 to 1.06$),{ }^{24}$ and $0.50(0.23$ to 1.10$),{ }^{27}$ (see fig 2 ), but the $95 \%$ confidence intervals for these studies crossed the line of no effect. The overall effect estimate showed a significant reduction of risk associated with acetazolamide $500 \mathrm{mg}$, with a combined odds ratio of 0.37 ( 0.26 to 0.52 ).

\section{Acetazolamide $750 \mathrm{mg}$ versus placebo}

Two studies (157 participants) compared acetazolamide 750 $\mathrm{mg}$ with placebo. Both indicated a statistically significant reduction in the risk of acute mountain sickness associated with acetazolamide $750 \mathrm{mg}$, with odds ratios of $0.30(0.12 \text { to } 0.75)^{15}$ and 0.10 (0.03 to 0.36$).^{28}$ The overall effect estimate in this group showed a significant reduction in risk of acute mountain sickness associated with acetazolamide $750 \mathrm{mg}$, with a combined odds ratio of 0.20 (0.10 to 0.41$)$.

\section{Numbers needed to treat}

The number needed to treat the number needed to treat was 6 ( $95 \%$ confidence interval 5 to 11 ) in the acetazolamide $250 \mathrm{mg}$ subgroup, 7 (6 to 9) in the $500 \mathrm{mg}$ subgroup, and 3 (3 to 5) in the $750 \mathrm{mg}$ subgroup.

\section{Adverse effects}

Side effects reported in some of the trials suggested a substantial increase in the incidence of paraesthesia among participants taking acetazolamide compared with placebo in all three dose specific groups (see supplementary table 2). The incidence of paraesthesia increased from $3.7 \%$ (placebo) to $49 \%$ (intervention) $^{5}$ and from $31 \%$ (placebo) to $76 \%$ (intervention) $)^{15}$ in the $250 \mathrm{mg}$ subgroup, from $0 \%$ (placebo) to $35 \%$ (intervention) $^{24}$ and from $10 \%$ (placebo) to $72 \%$ (intervention) ${ }^{13}$ in the $500 \mathrm{mg}$ subgroup, and from $31 \%$ (placebo) to $91 \%$ (intervention) ${ }^{15}$ in the $750 \mathrm{mg}$ subgroup. Other side effects reported were polyuria, rash, and dysgeusia. The frequency of micturition increased with use of acetazolamide. The biggest increase was in the $750 \mathrm{mg}$ subgroup, where incidence increased from $53 \%$ (placebo) to $60 \%$ (intervention) ${ }^{15}$ and from $0 \%$ (placebo) to $15 \%$ (intervention). ${ }^{28}$ Dysgeusia increased from $2 \%$ (placebo) to $11 \%$ (intervention) ${ }^{13}$ in one trial using $500 \mathrm{mg}$ daily and from $4 \%$ (placebo) to $14 \%$ (intervention) ${ }^{15}$ in one trial using $750 \mathrm{mg}$ daily. Different levels of dysgeusia were not evident in the two other trials comprising $250 \mathrm{mg}$ and $500 \mathrm{mg}$ treatment groups. ${ }^{1524}$

Five of the 11 studies $^{513152325}$ reported non-adherence to drug schedules (see supplementary table 3 ). No dose-response increase in non-adherence was obvious.

\section{Qualitative analysis of intervention effects Heterogeneity}

Heterogeneity between the four studies administering acetazolamide $250 \mathrm{mg}$ daily was low $\left(\mathrm{I}^{2}=15 \%, \mathrm{P}=0.32\right)$. No measurable heterogeneity was identified between the six studies forming the acetazolamide $500 \mathrm{mg}$ group $\left(\mathrm{I}^{2}=0 \%, \mathrm{P}=0.83\right)$. Heterogeneity of effects between the two trials administering $750 \mathrm{mg}$ acetazolamide daily was moderate $\left(\mathrm{I}^{2}=44 \%, \mathrm{P}=0.18\right)$. 
Comparison of fixed and random effects estimation of the intervention effect as recommended in the Cochrane handbook ${ }^{17}$ did not yield a difference in effect estimation within the 250 $\mathrm{mg}$ and $500 \mathrm{mg}$ treatment groups. Only a minor difference was identified within the $750 \mathrm{mg}$ group: fixed effects odds ratio $(0.20,95 \%$ confidence interval 0.10 to 0.41$)$ compared with random effects $(0.19,0.07$ to 0.52$)$. There was no evidence of funnel plot asymmetry (see supplementary fig 4), indicating the absence of publication bias. Assuming homogeneity, a fixed effects model was applied to estimate the intervention effect in the meta-analysis.

\section{Sensitivity analysis}

In a sensitivity analysis including only studies that used the Lake Louise scoring system to diagnose acute mountain sickness (fig $3 \Downarrow$ ), the estimate of intervention effects was similar between the original analysis and the sensitivity analyses, which included eight of the 11 original studies. In the $250 \mathrm{mg}$ treatment group the four included studies all applied the Lake Louise scoring system, ${ }^{5} 152526$ therefore sensitivity analysis was not needed. In the $500 \mathrm{mg}$ subgroup, four of the original six studies were analysed $^{1323-25}$ giving a combined odds ratio of $0.35(95 \%$ confidence interval 0.24 to 0.52 ) compared with the original odds ratio of 0.37 ( 0.26 to 0.52 ). Only one of the two studies applied the Lake Louise scoring system in the $750 \mathrm{mg}_{\text {group }}{ }^{15}$ resulting in a reduced treatment effect compared with the original analysis: odds ratio $0.30(0.12$ to 0.75$)$ compared with 0.20 (0.10 to 0.41$)$.

\section{Discussion}

This systematic review and meta-analysis summarises the current evidence on the efficacy of acetazolamide $250 \mathrm{mg}, 500$ $\mathrm{mg}$, and $750 \mathrm{mg}$ daily in the prevention of acute mountain sickness. A systematic search of relevant published and unpublished literature identified 11 trials for inclusion in the review. The results showed that at all three doses acetazolamide was efficacious in preventing acute mountain sickness above $3000 \mathrm{~m}$. Acetazolamide $250 \mathrm{mg}$ was the lowest effective dose for which there was evidence for this indication.

\section{Comparisons with other studies}

Results from this review do not support those of the original review on the topic published in $2000,{ }^{12}$ which concluded that doses of acetazolamide lower than $750 \mathrm{mg}$ were not effective in preventing acute mountain sickness. The results of the current review show the effectiveness of lower doses of acetazolamide ( $250 \mathrm{mg}$ and $500 \mathrm{mg}$ daily) in preventing acute mountain sickness and confirm the efficacy of acetazolamide $750 \mathrm{mg}$ as previously reported. ${ }^{12}$

An important difference between this review and the original review lies in the number of participants. In this review we analysed 1512 participants in three dose specific subgroup analyses, whereas in the original review 295 participants were analysed in the acetazolamide arm of the meta-analysis and the reviewers did not carry out a subgroup analysis for acetazolamide $250 \mathrm{mg}$ daily. ${ }^{12}$ Also, we included randomised placebo controlled trials only, whereas the original review included trials that were not placebo controlled. ${ }^{12}$

Our findings are in line with two recently published reviews. The first, a systematic shortcut review, ${ }^{30}$ analysed data relevant to several drug interventions for prevention of acute mountain sickness. Acetazolamide $250 \mathrm{mg}$ was shown to be effective in preventing the condition. The review and analysis of data from three trials gave a number needed to treat ranging from 3 to 8 for doses of acetazolamide ranging from $250 \mathrm{mg}$ to $750 \mathrm{mg}$.

The second published review, a systematic review and meta-analysis, ${ }^{31}$ analysed the efficacy of acetazolamide by testing the association between baseline risk and the efficacy of prophylaxis. The results support our findings that acetazolamide $250 \mathrm{mg}$ and $500 \mathrm{mg}$ daily are effective in preventing acute mountain sickness contrary to previous suggestions that doses of acetazolamide below $750 \mathrm{mg}$ do not work. ${ }^{12}$ This review concluded that efficacy of acetazolamide was lower with slow mode of ascent. Those who ascended to altitude by climbing were assessed as having a lower baseline risk for developing acute mountain sickness resulting in higher numbers needed to treat (5.3 to 6.5 in doses ranging from 250 $\mathrm{mg}$ to $750 \mathrm{mg}$ ) compared with those who ascended by a combination of transport and climbing (3.0 to 3.5 in doses ranging from $250 \mathrm{mg}$ to $750 \mathrm{mg}$ ). ${ }^{31}$ These values are based on the risk ratio derived from the main analysis that was applied to the average control event rate calculated for each subgroup. After two study authors independently assessed the full text articles we excluded from the review 10 of the studies ${ }^{41}$ 32-39 included in the second of the published reviews ${ }^{31}$ (see supplementary table 1 for reasons for exclusion). Our inclusion criteria specified that trials were required to randomise participants to either acetazolamide or placebo. This was not, however, a specific requirement of the second review, and one study $^{32}$ was included where all participants were given acetazolamide for three days before being randomised to intervention or placebo groups. We excluded trials that were not blinded, ${ }^{4}$ used hypobaric chambers to simulate ascent to altitude, ${ }^{38}$ or included the indigenous population (owing to the likelihood of acclimatisation).$^{37}$ One study included in the systematic review and meta-analysis by Kayser et $\mathrm{al}^{31}$ was excluded from our review because the same participants took part in both the intervention and placebo groups during two different ascents, and these were then compared with each other. ${ }^{40}$ The risk of acclimatisation on the second ascent was significant and some participants will have received acetazolamide on the first ascent and placebo on the second. We excluded three studies included in a previous review ${ }^{41-43}$ on the basis of the titles and abstracts not fitting our inclusion criteria. One of the studies was excluded as the primary outcome was assessment of the efficacy of acetazolamide $500 \mathrm{mg}$ daily in improving sleep disturbance. ${ }^{41}$ Furthermore, all participants received acetazolamide $500 \mathrm{mg}$ for three days before being allocated to either the intervention or the placebo groups. Another study was excluded because the primary outcome was measurement of plasma erythropoietin by radioimmunoassay to assess the association between acetazolamide and erythropoietin levels at altitude. ${ }^{42} \mathrm{~A}$ third study was excluded as the incidence of acute mountain sickness was not clearly reported among participants, instead altitude induced mood changes was the primary outcome reported. ${ }^{43}$ The rigorous approach to study selection and inclusion criteria of this review did not provide sufficient data for subgroup analysis based on mode of ascent.

\section{Strengths and limitations of this review}

The strength of this study is based on a thorough and systematic literature review. Relevant studies were identified by using a sensitive search strategy through electronic databases. We tried to identify additional published and unpublished studies in all languages. The review analysed a large sample of data and most of the studies included for analysis had adequate study sample sizes. This is a particular strength of the current review 
compared with some stand alone studies on high altitude. Trial coordinators are often unable to recruit adequate numbers of participants, making it difficult to draw firm conclusions from smaller studies. Heterogeneity among studies was low for the acetazolamide $250 \mathrm{mg}$ and $500 \mathrm{mg}$ subgroups.

The review does have some limitations. We acknowledge that acute mountain sickness constitutes a spectrum of symptoms of varying severity. Owing to the scope of the literature analysed, the studies included in the meta-analysis did not share a standard definition of acute mountain sickness to enable the incidence to be determined among participants. However, the sensitivity analysis of eight trials using the Lake Louise scoring system to diagnose acute mountain sickness showed a similar combined outcome when compared with the original analysis of all 11 trials. Furthermore, heterogeneity was similar for the acetazolamide $250 \mathrm{mg}$ and $500 \mathrm{mg}$ subgroups between the original and sensitivity analysis.

Five of the 11 studies enrolled participants at altitudes above $4000 \mathrm{~m}^{513222325}$ At these altitudes participants will have been partially acclimatised at the time of enrolment. It would have been more useful if the trials had recruited participants at lower altitudes (ideally $<2500 \mathrm{~m}$ ), to ensure that none were acclimatised before receiving the intervention.

The mean final altitude of the included studies was $4619 \mathrm{~m}$ (range 3800-5000 m). Symptoms of acute mountain sickness can occur at altitudes of $3000 \mathrm{~m}$ and below. The rigorous approach of this review meant that no studies with final altitudes below $3800 \mathrm{~m}$ were found to be eligible for inclusion. Owing to a lack of data among the included trials, no firm conclusion can be made about the efficacy of acetazolamide at altitudes below $3800 \mathrm{~m}$. However, a small study with assessment at 3650 $\mathrm{m}$ using the acute mountain sickness-cerebral and acute mountain sickness-respiratory scores, found evidence to suggest that acetazolamide $500 \mathrm{mg}$ is effective in reducing the incidence of acute mountain sickness compared with placebo. ${ }^{39}$ It is likely that acetazolamide does have some beneficial effect in reducing symptoms of acute mountain sickness at moderate altitudes, as suggested by that study, ${ }^{39}$ and possible prophylactic benefit must be weighed against the risk of adverse effects.

The findings of the acetazolamide $750 \mathrm{mg}$ subgroup analysis were based on data from only two studies. ${ }^{15} 28$ This brings into question the reliability and reproducibility of the results for acetazolamide $750 \mathrm{mg}$. Both studies included in the subgroup analysis, however, were of an acceptable size for analysis. The quality of some of the studies in the review was low. Overall blinding of participants and outcome assessment was poor among the included studies. One study suggested that side effects induced by acetazolamide may compromise blinding. ${ }^{28}$ The side effects of acetazolamide reported among the trials in this review include paresthesia, polyuria, rash, and dysgeusia (see supplementary table 2). The incidence of paraesthesia increased substantially in the intervention groups. The association between high dose ( $750 \mathrm{mg}$ daily) acetazolamide and an increased incidence of adverse effects discussed in three studies ${ }^{26}{ }^{27}$ was to an extent supported by the observations in the different dose specific subgroups, suggesting that the greatest increase in adverse effects between placebo and intervention groups occurred in the $750 \mathrm{mg}$ subgroup for all four side effects analysed. Increased rates of adverse events in the intervention groups are a possible threat to blinding. The data extracted were descriptive, revealing tendencies in side effects that were not affected by adherence to treatment schedules. Side effects were also common in the placebo groups and their occurrence would not necessarily have led to disclosure of drugs. Five of the 11 studies also showed a high risk of attrition bias. The results should be interpreted with care.

\section{Implications for future practice}

This systematic review and meta-analysis provide evidence that lower daily doses of acetazolamide (250 mg and $500 \mathrm{mg}$ ) are effective for prophylaxis of acute mountain sickness at high altitude. When choosing the appropriate dose of acetazolamide in clinical practice, clinicians should consult patients on the benefits and harms of higher $(750 \mathrm{mg})$ compared with lower (250 $\mathrm{mg}$ and $500 \mathrm{mg}$ ) doses of the drug.

Lower doses of acetazolamide have been shown to be effective in preventing acute mountain sickness, and data extracted from the included studies indicate that acetazolamide $750 \mathrm{mg}$ is associated with a higher risk of adverse effects (paraesthesia, polyuria, rash, and dysgeusia). People who are particularly eager to avoid acute mountain sickness might still prefer the higher dose of acetazolamide $(750 \mathrm{mg})$ as the number needed to treat for this subgroup was 3 compared with 6 for the $250 \mathrm{mg}$ dose and 7 for the $500 \mathrm{mg}$ dose. Nevertheless, when prescribing this drug clinicians should consider the association between higher doses of acetazolamide and the increased risk of adverse effects, particularly paraesthesia.

\section{Future research and unanswered questions}

This review provides a definitive answer to a much discussed and disputed subject of the lowest effective dose of acetazolamide for prophylaxis of acute mountain sickness. Future research should seek to report relevant outcomes thoroughly and consistently. To produce comparable data the starting and final altitudes should be clearly stated and should be the same for all study participants. The rate and duration of ascent and total length of journey should be reported to allow further analysis of the relation between ascent rate and dose specific efficacy of acetazolamide. Future research that assesses participants for acute mountain sickness or seeks to diagnose acute mountain sickness among participants should use a validated and widely implemented diagnostic tool. We recommend that studies use the Lake Louise scoring system to ensure consistency and improve the future comparison of study data.

A high proportion of trials in the current literature enrol participants at altitudes above $3000 \mathrm{~m}$, which has the risk of partial acclimatisation of participants at the time of enrolment. A large trial, assessing the efficacy of acetazolamide and recruiting participants from low altitudes would be valuable to tackle the lack of data currently available in this area.

Previous trials assessing the efficacy of acetazolamide for prophylaxis of acute mountain sickness primarily recruited mountaineering enthusiasts. With increasing numbers of the general population now ascending to high altitudes, a study recruiting participants from this population may provide more relevant information for prescribing acetazolamide in primary care settings.

It is unclear from the literature whether acetazolamide is effective in preventing acute mountain sickness during rapid ascent to altitude such as flying to high altitudes from sea level, or during emergency rescue at high altitudes. Two small studies have indicated that acetazolamide $500 \mathrm{mg}$ and $750 \mathrm{mg}$ have some efficacy for preventing or reducing acute mountain sickness during rapid ascent to altitude. One study assessed acetazolamide $750 \mathrm{mg}$ daily during rapid ascent (sea level to $4394 \mathrm{~m}$ ) in 33.5 hours on average, ${ }^{28}$ and another ${ }^{34}$ assessed acetazolamide $500 \mathrm{mg}$ daily during rapid ascent to altitude (sea 
level to $3630 \mathrm{~m}$ ) in just over 24 hours. A study assessing the efficacy of different doses of acetazolamide during rapid ascent to altitude would be useful.

\section{Conclusions}

Our systematic review and meta-analysis provides evidence that acetazolamide at doses of $250 \mathrm{mg}, 500 \mathrm{mg}$, and $750 \mathrm{mg}$ daily are all effective in preventing acute mountain sickness at high altitudes. Acetazolamide $250 \mathrm{mg}$ daily was the lowest effective dose for which evidence exists.

Contributors: EVL designed and implemented the literature search, designed the data extraction tool, extracted the data, completed the data analysis, and drafted and revised the manuscript. EVL is guarantor. AJA designed and supervised the literature search and data extraction and drafted and revised the paper. VG implemented the literature search and data extraction and revised the manuscript. AS monitored the data extraction and designed and implemented the risk of bias and qualitative analysis. MPWG designed the literature search and study methods and reviewed the manuscript.

Funding: EVL and VG have received funding from the University of Nottingham to complete the study. No other funding was received for this study.

Competing interests: All authors have completed the ICMJE uniform disclosure form at www.icmje.org/coi_disclosure.pdf (available on request from the corresponding author) and declare: EVL and VG had support from the University of Nottingham for the submitted work; no financial relationships with any organisations that might have an interest in the submitted work in the previous three years; no other relationships or activities that influenced the submitted work.

Ethical approval: Not required.

Data sharing: No additional data available.

1 Salisbury R, Hawley E. The Himalaya by the numbers: a statistical analysis of mountaineering in the Nepal Himalaya. Vajra, 2011

2 Hunt L. Mount Kilimanjaro: climb and punishment. Telegraph Travel, 2010.

3 Imray C, Booth A, Wright A, Bradwell A. Acute altitude illnesses. BMJ 2011;343:d4943.

4 Moraga FA, Flores A, Serra J, Esnaola C, Barriento C. Ginkgo biloba decreases acute mountain sickness in people ascending to high altitude at Ollague $(3696 \mathrm{~m})$ in northern Chile. Wilderness Environ Med 2007;18:251-7.

5 Basnyat B, Gertsch JH, Johnson EW, Castro-Marin F, Inoue Y, Yeh C. Efficacy of low-dose acetazolamide (125 mg BID) for the prophylaxis of acute mountain sickness: a prospective, double-blind, randomized, placebo-controlled trial. High Alt Med Biol 2003;4:45-52.

6 Kayser B, Hulsebosch R, Bosch F. Low-dose acetylsalicylic acid analog and acetazolamide for prevention of acute mountain sickness. High Alti Med Biol 2008;9:15-23.

7 Joint Formulary Committee. British National Formulary. BMA, RPS 2011. (No 61.)

8 Bailey DM, Davies B. Acute mountain sickness; prophylactic benefits of antioxidant vitamin supplementation at high altitude. High Alt Med Biol 2001;2:21-9.

9 Gertsch JH, Seto TB, Mor J, Onopa J. Ginkgo biloba for the prevention of severe acute mountain sickness (AMS) starting one day before rapid ascent. High Alt Med Biol 2002;3:29-37.

10 Roncin JP, Schwartz F, D'Arbigny P. EGb 761 in control of acute mountain sickness and vascular reactivity to cold exposure. Aviat Space Environ Med 1996;67:445-52.

11 Hussain MM, Aslam M, Khan Z. Acute mountain sickness score and hypoxemia. J Pak Med Assoc 2001:51:173-9.

12 Dumont L, Mardirosoff C, Tramer MR. Efficacy and harm of pharmacological prevention of acute mountain sickness: quantitative systematic review. BMJ 2000;321:267-72.

13 Gertsch JH, Basnyat B, Johnson EW, Onopa J, Holck PS. Randomised, double blind, placebo controlled comparison of ginkgo biloba and acetazolamide for prevention of acute mountain sickness among Himalayan trekkers: the prevention of high altitude illness trial (PHAIT). BMJ 2004;328:797.

14 Hackett PH, Roach RC. High-altitude illness. N Engl J Med 2001;107-14.

15 Basnyat B, Gertsch JH, Holck PS, Johnson EW, Luks AM, Donham BP. Acetazolamide $125 \mathrm{mg}$ BD is not significantly different from $375 \mathrm{mg} \mathrm{BD}$ in the prevention of acute mountain sickness: the prophylactic acetazolamide dosage comparison for efficacy (PACE) trial. High Alt Med Biol 2006;7:17-27.

16 Roach RC, Bärtsch P, Hackett PH, Oelz O, Committee. LLASC. The Lake Louise acute mountain sickness scoring system. In: Sutton JR, Coates G, Huston CS, eds. Hypoxia and molecular medicine: proceedings of the 8th international hypoxia symposium. Queens City Printers 1993;272-4.

17 Higgins JP, Green S. Cochrane Handbook for Systematic Reviews of Interventions. Version 5.1.0 [updated March 2011]. Cochrane Collaboration 2011.

18 Higgins JP, Thompson SG. Quantifying heterogeneity in a meta-analysis. Stat Med 2002;21:1539-58

19 Higgins JP, Thompson SG, Deeks JJ, Altman DG. Measuring inconsistency in meta-analysis. BMJ 2003;557-60.

20 Olzowy M. Prevention of altitude sickness. Fortschr Med 1975;93:1415-22.

21 Utz G, Schlierf G, Barth P, Linhart P, Wollenweber J. Prevention of acute mountain sickness using acetazolamide. Munch Med Wochenschr 1970;112:1122-4.

22 Basnyat B, Hargrove J, Holck PS, Srivastav S, Alekh K, Ghimire LV, et al. Acetazolamide fails to decrease pulmonary artery pressure at high altitude in partially acclimatized humans. High Alt Med Biol 2008;9:209-16.

23 Basnyat B, Holck PS, Pun M, Halverson S, Szawarski P, Gertsch J, et al. Spironolactone does not prevent acute mountain sickness: a prospective, double-blind, randomized, placebo-controlled trial by SPACE Trial Group (spironolactone and acetazolamide trial in the prevention of acute mountain sickness group). Wilderness Environ Med 2011;22:15-22.

24 Chow T, Browne V, Heileson HL, Wallace D, Anholm J, Green SM. Ginkgo biloba and acetazolamide prophylaxis for acute mountain sickness: a randomized, placebo-controlled trial. Arch Intern Med 2005;165:296-301.

25 Gertsch JH, Lipman GS, Holck PS, Merritt A, Mulcahy A, Fisher RS, et al. Prospective, double-blind, randomized, placebo-controlled comparison of acetazolamide versus ibuprofen for prophylaxis against high altitude headache: the Headache Evaluation at Altitude Trial (HEAT). Wilderness Environ Med 2010;21:236-43.

26 Van Patot MCT, Leadbetter G 3rd, Keyes LE, Maakestad KM, Olson S, Hackett PH. Prophylactic low-dose acetazolamide reduces the incidence and severity of acute mountain sickness. High Alt Med Biol 2008:9:289-93.

27 Hackett PH, Rennie D, Levine HD. The incidence, importance, and prophylaxis of acute mountain sickness. Lancet 1976;2:1149-55

28 Larson EB, Roach RC, Schoene RB, Hornbein TF. Acute mountain sickness and acetazolamide. Clinical efficacy and effect on ventilation. JAMA 1982;248:328-32.

29 Burki NK, Khan SA, Hameed MA. The effects of acetazolamide on the ventilatory response to high altitude hypoxia. Chest 1992;101:736-41.

30 Seupaul RA, Welch J, Malka S, Emmett T. Pharmacologic prophylaxis for acute mountain sickness: a systematic shortcut review. Ann Emerg Med 2012;59:307-17.

31 Kayser B, Dumont L, Lysakowski C, Combescure C, Haller G, Tramer MR. Reappraisal of acetazolamide for the prevention of acute mountain sickness: a systematic review and meta-analysis. High Alt Med Biol 2012;13:82-92.

32 Bradwell AR, Burnett D, Davies F. Acetazolamide in control of acute mountain sickness. Lancet 1981:1:180-3.

33 Carlsten C, Swenson ER, Ruoss S. A dose-response study of acetazolamide for acute mountain sickness prophylaxis in vacationing tourists at 12,000 feet $(3630 \mathrm{~m})$. High Alt Med Biol 2004;5:33-9.

34 Ellsworth AJ, Larson EB, Strickland D. A randomized trial of dexamethasone and acetazolamide for acute mountain sickness prophylaxis. Am J Med 1987;83:1024-30.

35 Fischer R, Lang SM, Leitl M, Thiere M, Steiner U, Huber RM. Theophylline and acetazolamide reduce sleep-disordered breathing at high altitude. Eur Respir $J$ 2004;23:47-52.

36 Greene MK, Kerr AM, McIntosh IB, Prescott RJ. Acetazolamide in prevention of acute mountain sickness: a double-blind controlled cross-over study. BMJ 1981;283:811-3.

37 Hillenbrand P, Pahari AK, Soon Y, Subedi D, Bajracharya R, Gurung P, et al. Prevention of acute mountain sickness by acetazolamide in Nepali porters: a double-blind controlled trial. Wilderness Environ Med 2006;17:87-93.

38 Kronenberg RS, Cain SM. Hastening respiratory acclimatization to altitude with benzolamide (CL 11,366). Aerospace Med 1967;39:296-300.

39 Zell SC, Goodman PH. Acetazolamide and dexamethasone in the prevention of acute mountain sickness. West J Med 1988;148:541-5.

40 Ellsworth AJ, Meyer EF, Larson EB. Acetazolamide or dexamethasone use versus placebo to prevent acute mountain sickness on Mount Rainier. West J Med 1991;154:289-93.

41 Nicholson AN, Smith PA, Stone BM, Bradwell AR, Coote JH. Altitude insomnia: studies during an expedition to the Himalayas. Sleep 1988;11:354-61.

42 Reinhart WH, Goerre S, Barstch P. Acetazolamide reduces the erythropoietin response to hypoxia at high altitude in humans. J Wilderness Med 1994;5:312-7.

43 Banderet LE. Self-rated moods of humans at $4300 \mathrm{~m}$ pretreated with placebo or acetazolamide plus staging. Aviation Space Environ Med 1977;48:19-22.

Accepted: 25 September 2012

\section{Cite this as: BMJ 2012;345:e6779}

This is an open-access article distributed under the terms of the Creative Commons Attribution Non-commercial License, which permits use, distribution, and reproduction in any medium, provided the original work is properly cited, the use is non commercial and is otherwise in compliance with the license. See: http://creativecommons.org/licenses/by$\mathrm{nc} / 2.0 /$ and http://creativecommons.org/licenses/by-nc/2.0/legalcode. 


\section{What is already known on this topic}

Acute mountain sickness is commonly encountered at high altitudes

A systematic review from 2000 showed that acetazolamide $750 \mathrm{mg}$ was effective in preventing acute mountain sickness

\section{What this study adds}

This systematic review found that acetazolamide $250 \mathrm{mg}$ and $500 \mathrm{mg}$ daily are also effective in preventing acute mountain sickness Acetazolamide $250 \mathrm{mg}$ daily was the lowest dose with evidence on effectiveness in preventing acute mountain sickness

\section{Tables}

\section{Table 1| Characteristics of included randomised controlled clinical trials}

\begin{tabular}{|c|c|c|c|c|c|c|}
\hline $\begin{array}{l}\text { Study, } \\
\text { setting }\end{array}$ & $\begin{array}{l}\text { Final } \\
\text { altitude } \\
(\mathrm{m})\end{array}$ & $\begin{array}{l}\text { Method of } \\
\text { randomisation* }\end{array}$ & Participants & Intervention & Outcomes & Notes \\
\hline $\begin{array}{l}\text { Basnyat } \\
2003^{5}, \text { Mount } \\
\text { Everest, } \\
\text { Nepal }\end{array}$ & 4937 & $\begin{array}{l}\text { Drug container } \\
\text { allocation on site }\end{array}$ & $\begin{array}{l}\mathrm{n}=155 \text { (mean age } 34.8) \\
67 \% \text { male. Intervention: } \\
74 \text { (mean age } 35.8) \text {. } \\
\text { Control: } 81 \text { (mean age } \\
\text { 33.9). No AMS before } \\
\text { enrolment at base camp }\end{array}$ & $\begin{array}{l}\text { Starting on day } 1 \text { of ascent to } \\
\text { altitude, acetazolamide } 125 \\
\text { mg twice daily or visually } \\
\text { matched placebo twice daily. } \\
\text { Treatment for 2-3 days } \\
\text { depending on route of ascent }\end{array}$ & $\begin{array}{l}\text { Diagnosis of AMS as defined } \\
\text { by LLSS }\end{array}$ & $\begin{array}{l}\text { Participants were recruited at } \\
\text { Pheriche }(4243 \mathrm{~m}) \text {, which may } \\
\text { have introduced selection bias } \\
\text { and lowered incidence of AMS } \\
\text { among participants }\end{array}$ \\
\hline $\begin{array}{l}\text { Basnyat } \\
2006^{15} \\
\text { Mount } \\
\text { Everest, } \\
\text { Nepal }\end{array}$ & 4828 & $\begin{array}{l}\text { Assignment } \\
\text { codes, prepared } \\
\text { by independent } \\
\text { party }\end{array}$ & $\begin{array}{l}\mathrm{n}=204 \text { (mean age } 37.9) \\
64.7 \% \text { male. Intervention } \\
(250 \mathrm{mg}): 58 \text { (mean age } \\
36.8) \text {, intervention ( } 750 \\
\mathrm{mg}): 68 \text { (mean age } 38.9) \text {. } \\
\text { Control ( } 250 \mathrm{mg}): 29, \\
\text { control ( } 750 \mathrm{mg}): 30 \text {. No } \\
\text { AMS before enrolment at } \\
\text { base camp }\end{array}$ & $\begin{array}{l}\text { Acetazolamide } 125 \mathrm{mg} \text { twice } \\
\text { daily, } 375 \mathrm{mg} \text { twice daily, or } \\
\text { visually matched placebo } \\
\text { twice daily (control group). } \\
\text { Treatment for } 6 \text { days }\end{array}$ & $\begin{array}{l}\text { Diagnosis of AMS as defined } \\
\text { by LLSS }\end{array}$ & $\begin{array}{l}\text { Study had one control arm and } \\
\text { two intervention arms for each } \\
\text { dose of acetazolamide. To allow } \\
\text { meta-analysis the control group } \\
\text { was divided in two to allow two } \\
\text { separate comparison of } \\
\text { subgroup against control group. } \\
\text { The original control group of } 59 \\
\text { participants was divided as } \\
\text { above. Side effects of } \\
\text { acetazolamide were more } \\
\text { pronounced in } 750 \text { mg group, } \\
\text { with } 91 \% \text { of participants } \\
\text { experiencing side effects } \\
\text { compared with } 71 \% \text { in } 250 \mathrm{mg} \\
\text { group }\end{array}$ \\
\hline $\begin{array}{l}\text { Basnyat } \\
2008^{22} \\
\text { Nepal }\end{array}$ & 5000 & $\begin{array}{l}\text { Computer } \\
\text { generated }\end{array}$ & $\begin{array}{l}\mathrm{n}=364 \text { (mean age } 38.6 \text {, } \\
\text { range } 18-65) ; 62.6 \% \\
\text { male. Intervention: } 187 \\
\text { (mean age } 37.9) \text {. Control: } \\
177 \text { (mean age } 39.4 \text { ). No } \\
\text { AMS before enrolment at } \\
\text { base camp }\end{array}$ & $\begin{array}{l}\text { Starting on day } 1 \text { of ascent, } \\
\text { self administered } \\
\text { acetazolamide } 250 \mathrm{mg} \text { twice } \\
\text { daily or visually matched } \\
\text { placebo twice daily. Treatment } \\
\text { for } 4 \text { days }\end{array}$ & $\begin{array}{l}\text { Evaluation of participants for } \\
\text { HAPE and evaluation of } \\
\text { pulmonary artery systolic } \\
\text { pressure using Doppler } \\
\text { echocardiography. } \\
\text { Secondary outcomes were } \\
\text { incidence of AMS, HAPE, } \\
\text { and HACE. AMS was } \\
\text { diagnosed using LLSS. } \\
\text { Symptoms of AMS were } \\
\text { assessed by upper level } \\
\text { medical student or doctor on } \\
\text { arrival at final altitude in } \\
\text { Lobuche }\end{array}$ & $\begin{array}{l}\text { Author was contacted to clarify } \\
\text { raw data used to determine } \\
\text { incidence of AMS among } \\
\text { participants }\end{array}$ \\
\hline
\end{tabular}

Basnyat 5000 Not described $n=159$ (mean age 38.3); Starting on day 1 of ascent, Diagnosis of AMS as defined

$2011^{23}$, 67\% male. Intervention: acetazolamide $250 \mathrm{mg}$ twice by LLSS

Mount

95 (mean age 37.2.). daily, spironolactone $50 \mathrm{mg}$

Everest,

Control: 64 (mean age twice daily, or visually

Nepal 39.4). No AMS before matched placebo twice daily.

enrolment at base camp Spironolactone arm was

excluded from analysis.

Treatment for 4 days

Burki $1992^{29}, \quad 4450$ Not described $n=12$ (mean age $20.3 \quad$ Starting on day 1 before $\quad$ Amelioration of AMS Unpublished data retrieved (N K Rawalpindi, $\quad$ years); $100 \%$ male. $\quad$ ascent, acetazolamide $250 \mathrm{mg}$ symptoms as defined by Burki, 2011). Primary author was

Pakistan Intervention: 6. Control: 6. twice daily or placebo twice

No AMS before enrolment daily. Treatment for 2 days

at base camp

symptom score; "clinical evaluation for AMS consisted of evaluation of dizziness, AMS. Author confirmed that AMS nausea/vomiting and was defined as being present in headache on a grade of 0-2 patients with a positive score (+) 
Table 1 (continued)

\begin{tabular}{|c|c|c|c|c|c|c|}
\hline \multirow[t]{2}{*}{$\begin{array}{l}\text { Study, } \\
\text { setting }\end{array}$} & $\begin{array}{l}\text { Final } \\
\text { altitude } \\
\text { (m) }\end{array}$ & $\begin{array}{c}\text { Method of } \\
\text { randomisation* }\end{array}$ & Participants & Intervention & Outcomes & Notes \\
\hline & & & & & $\begin{array}{l}(-,+,++) \text { " Incidence of AMS } \\
\text { among participants was } \\
\text { extracted from published raw } \\
\text { data as defined using } \\
\text { symptom scale }\end{array}$ & $\begin{array}{l}\text { in at least one category; } \\
\text { nausea/vomiting or headache. } \\
\text { Incidence was extracted from } \\
\text { published data using this } \\
\text { definition }\end{array}$ \\
\hline
\end{tabular}

Chow $2005^{24} 3800$ Drawing labelled $n=40$ (mean age 32.75); Starting on day 1 before Diagnosis of AMS as defined Base camps were situated at cards at random $57.5 \%$ male. Intervention: ascent, acetazolamide $250 \mathrm{mg}$ by LLSS $\quad 4280 \mathrm{~m}$ and $4358 \mathrm{~m}$. Some may 20. Control: 20. No AMS twice daily, $120 \mathrm{mg}$ ginkgo before enrolment at base biloba twice daily, or visually camp matched placebo twice daily. have developed AMS before, or on reaching base camp and would have been excluded from The ginkgo biloba arm was excluded from analysis. Treatment for 3 days study. This may have introduced selection bias and lowered incidence of AMS among participants

\begin{tabular}{lll}
\hline Gertsch & 4928 & $\begin{array}{l}\text { Computer } \\
\text { generated }\end{array}$ \\
$2004^{13}$, & & genes
\end{tabular}

Mount

Everest,

Nepal $\mathrm{n}=487$ (mean age $36.6 \quad$ Acetazolamide $250 \mathrm{mg}$ twice Diagnosis of AMS as defined years); $69 \%$ male. daily beginning at base camp, by LLSS

Intervention: 118. Control: where a minimum of three 119. No AMS before doses were taken before enrolment at base camp ascent, ginkgo biloba $120 \mathrm{mg}$

twice daily, ginkgo biloba 120 $\mathrm{mg}$, and acetazolamide 250 mg twice daily or placebo tablet twice daily. Treatment for 4.7 days on average

Gertsch 4928 Computer $n=265$ (mean age $38.3 \quad$ Acetazolamide $85 \mathrm{mg}$

$2010^{25}$, generated

Mount

Everest,

Nepal beginning at bas years); $71.1 \%$ ma Intervention: 97 . Control: where minimum of three 65. No AMS before doses were taken before enrolment at base camp ascent, ibuprofen $600 \mathrm{mg}$, or visually matched placebo three times daily. (Study was assigned to $250 \mathrm{mg}$ analysis.) Treatment length not clear

\begin{tabular}{|c|c|c|c|c|}
\hline $\begin{array}{l}\text { Hackett } \\
1976^{27} \\
\text { Mount } \\
\text { Everest, } \\
\text { Nepal }\end{array}$ & 4243 & Coded bags & $\begin{array}{l}\mathrm{n}=278 \text { (mean age } 33 \\
\text { years); } 70.8 \% \text { male. } \\
\text { Intervention: } 71 \text {. Control: } \\
\text { 49. Control (no tablets): } \\
\text { 158. No AMS before } \\
\text { enrolment at base camp }\end{array}$ & $\begin{array}{l}\text { Starting at base camp, } \\
\text { acetazolamide } 250 \mathrm{mg} \text { twice } \\
\text { daily, placebo twice daily, or } \\
\text { no tablets. Treatment for } 4 \\
\text { days }\end{array}$ \\
\hline
\end{tabular}
enrolment at base camp

Incidence of AMS as defined by self completed symptom questionnaire assessing headache, nausea, anorexia, dizziness, and insomnia. "Those subjects with a total acetazolamide group for data

Diagnosis of headache as Base camps were situated at defined by LLSS. Incidence $4280 \mathrm{~m}$ and $4358 \mathrm{~m}$. Some may of AMS was derived from have developed AMS before, or data using LLSS on reaching base camp and would have been excluded from study. This may have introduced selection bias and lowered incidence of AMS among participants score of 2 or more were said to have AMS." To correlate severity of illness to predetermined variables within study population. Variation of AMS incidence depending on mode of ascent to Lukla (trekking from Katmandu or flight to Lukla)

\begin{tabular}{|c|c|c|c|c|c|c|}
\hline $\begin{array}{l}\text { Larson } \\
1982^{28}, \\
\text { Mount } \\
\text { Rainer, USA }\end{array}$ & 4394 & $\begin{array}{l}\text { Random } \\
\text { numbers table }\end{array}$ & $\begin{array}{l}\mathrm{n}=54 \text { ( age range } 21-48 \\
\text { years); } 83.4 \% \text { male. } \\
\text { Intervention: } 29 \text {. Control: } \\
\text { 25. No AMS before } \\
\text { enrolment at base camp }\end{array}$ & $\begin{array}{l}\text { Every eight hours, beginning } \\
\text { one day before ascent, } \\
\text { acetazolamide } 250 \mathrm{mg} \text { or } \\
\text { placebo three times daily. } \\
\text { Treatment for up to } 48 \text { hours } \\
\text { depending on time taken to } \\
\text { reach summit }\end{array}$ & $\begin{array}{l}\text { Main outcome was diagnosis } \\
\text { of AMS as defined by } \\
\text { general high altitude } \\
\text { symptom questionnaire. } \\
\text { "AMS was arbitrarily defined } \\
\text { as headache of moderate or } \\
\text { greater severity, nausea, of } \\
\text { slight or greater severity, or } \\
\text { both" }\end{array}$ & $\begin{array}{l}31 \text { participants from intervention } \\
\text { group guessed correctly that they } \\
\text { were receiving acetazolamide as } \\
\text { opposed to placebo. This may } \\
\text { have been due to side effects } \\
\text { that higher doses of } \\
\text { acetazolamide induce such as } \\
\text { diuresis and paresthesia. This } \\
\text { may introduce performance bias }\end{array}$ \\
\hline $\begin{array}{l}\text { Van Patot } \\
2008^{26}, \\
\text { Mount } \\
\text { Rainer, USA }\end{array}$ & 4394 & $\begin{array}{l}\text { Random } \\
\text { numbers table }\end{array}$ & $\begin{array}{l}\mathrm{n}=54 \text { (age range } 21-48 \\
\text { years); } 83.4 \% \text { male. } \\
\text { Intervention: } 29 \text {. Control: } \\
\text { 25. No AMS before } \\
\text { enrolment at base camp }\end{array}$ & $\begin{array}{l}\text { Starting one day before } \\
\text { ascent, acetazolamide } 250 \mathrm{mg} \\
\text { or placebo three times daily. } \\
\text { Treatment for up to } 48 \text { hours } \\
\text { depending on time taken to } \\
\text { reach summit }\end{array}$ & $\begin{array}{l}\text { Main outcome was diagnosis } \\
\text { of AMS as defined by AMS-C } \\
\text { and LLSS. Two assessment } \\
\text { methods provided similar } \\
\text { results and were positively } \\
\text { correlated. } 250 \text { mg daily }\end{array}$ & $\begin{array}{l}31 \text { participants from intervention } \\
\text { group guessed correctly that they } \\
\text { were receiving acetazolamide as } \\
\text { opposed to placebo. This may } \\
\text { have been due to side effects } \\
\text { that higher doses of }\end{array}$ \\
\hline
\end{tabular}


Table 1 (continued)

\begin{tabular}{|c|c|c|c|c|c|c|}
\hline \multirow[t]{2}{*}{$\begin{array}{l}\text { Study, } \\
\text { setting }\end{array}$} & $\begin{array}{l}\text { Final } \\
\text { altitude } \\
(\mathrm{m})\end{array}$ & $\begin{array}{l}\text { Method of } \\
\text { randomisation* }\end{array}$ & Participants & Intervention & Outcomes & Notes \\
\hline & & & & & $\begin{array}{l}\text { reduced both severity (based } \\
\text { on score) and AMS } \\
\text { incidence, regardless of AMS } \\
\text { assessment criteria used }\end{array}$ & $\begin{array}{l}\text { acetazolamide induce such as } \\
\text { diuresis and paresthesia. This } \\
\text { may introduce performance bias }\end{array}$ \\
\hline
\end{tabular}

AMS=acute mountain sickness; LLSS=Lake Louise scoring system; HAPE=high altitude pulmonary embolism; HACE=high altitude cerebral oedema; AMS-C=acute mountain sickness-cerebral.

*All were randomised, double blind, placebo controlled clinical trials. 
Table 2| Risk of bias of included studies

\begin{tabular}{|c|c|c|c|c|c|c|}
\hline Trial & $\begin{array}{l}\text { Sequence } \\
\text { generation }\end{array}$ & $\begin{array}{c}\text { Allocation } \\
\text { concealment }\end{array}$ & $\begin{array}{c}\text { Blinding of } \\
\text { participants and staff }\end{array}$ & $\begin{array}{l}\text { Blinding of outcome } \\
\text { assessment }\end{array}$ & $\begin{array}{c}\text { Incomplete outcome } \\
\text { data }\end{array}$ & $\begin{array}{l}\text { Selective outcome } \\
\text { reporting }\end{array}$ \\
\hline Basnyat $2003^{5}$ & Adequate & Adequate & Adequate & Adequate & Inadequate & Adequate \\
\hline Basnyat $2006^{15}$ & Adequate & Adequate & Adequate & Adequate & Inadequate & Unclear \\
\hline Basnyat $2008^{22}$ & Adequate & Adequate & Adequate & Unclear & Adequate & Unclear \\
\hline Basnyat $2011^{23}$ & Unclear & Adequate & Adequate & Unclear & Adequate & Unclear \\
\hline Burki $1992^{29}$ & Unclear & Unclear & Adequate & Unclear & Adequate & Inadequate \\
\hline Chow $2005^{24}$ & Adequate & Adequate & Adequate & Adequate & Adequate & Unclear \\
\hline Gertsch $2004^{13}$ & Adequate & Adequate & Unclear & Unclear & Adequate & Unclear \\
\hline Gertsch $2010^{25}$ & Adequate & Adequate & Unclear & Unclear & Inadequate & Unclear \\
\hline Hackett $1976^{27}$ & Unclear & Adequate & Unclear & Unclear & Inadequate & Unclear \\
\hline Larson $1982^{28}$ & Adequate & Adequate & Inadequate & Unclear & Inadequate & Unclear \\
\hline Van Patot $2008^{26}$ & Adequate & Adequate & Unclear & Unclear & Adequate & Adequate \\
\hline
\end{tabular}


Table 3| Efficacy of acetazolamide by dose

\begin{tabular}{|c|c|c|c|c|c|c|c|}
\hline \multirow[b]{2}{*}{ Dose (mg) } & \multirow[b]{2}{*}{ No of participants } & \multicolumn{2}{|c|}{ Event rate } & \multirow[b]{2}{*}{ Relative risk (95\% Cl) } & \multirow[b]{2}{*}{ Odds ratio $(95 \% \mathrm{Cl})$} & \multirow[b]{2}{*}{ Quality of evidence* } & \multirow{2}{*}{$\begin{array}{l}\text { Number needed to treat } \\
\qquad(95 \% \mathrm{Cl})\end{array}$} \\
\hline & & Control & Experimental & & & & \\
\hline 250 & 448 & 0.35 & 0.19 & 0.54 (0.39 to 0.74$)$ & 0.41 (0.26 to 0.64$)$ & High & $6(5$ to 11$)$ \\
\hline 500 & 907 & 0.30 & 0.14 & 0.47 (0.36 to 0.62$)$ & 0.37 (0.26 to 0.52$)$ & High & 7 (6 to 9$)$ \\
\hline 750 & 157 & 0.56 & 0.20 & 0.35 (0.21 to 0.57$)$ & $0.20(0.10$ to 0.41$)$ & Moderate & 3 (3 to 5 ) \\
\hline Subtotal & 1512 & 0.33 & 0.16 & 0.47 (0.39 to 0.57$)$ & 0.36 (0.28 to 0.46$)$ & - & - \\
\hline
\end{tabular}

*According to grading of recommendations assessment, development and evaluation. 


\section{Figures}

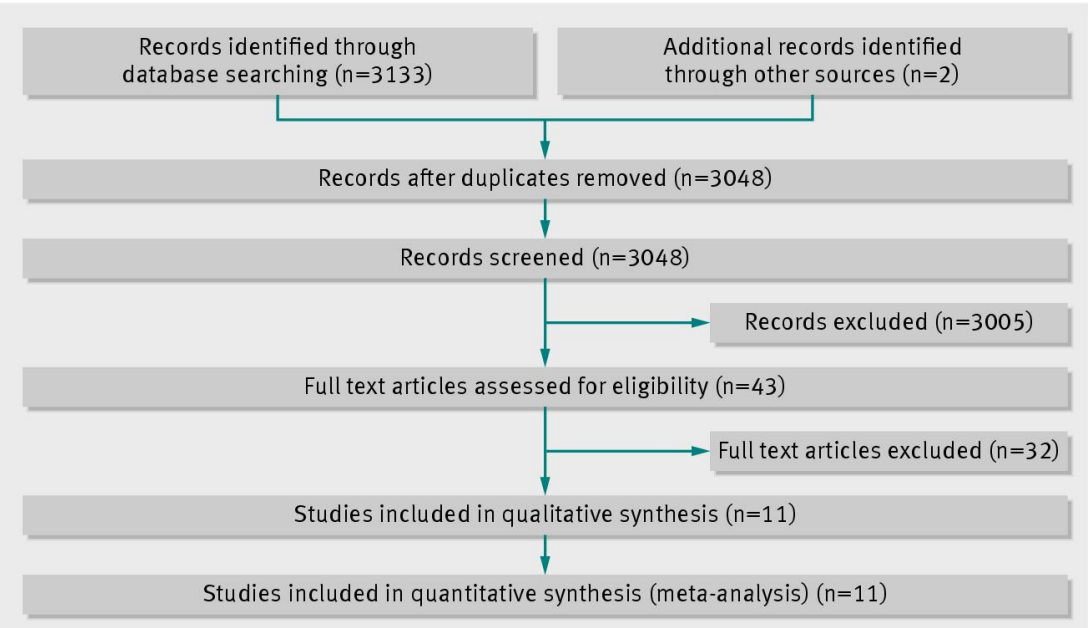

Fig 1 Selection of randomised trials for inclusion

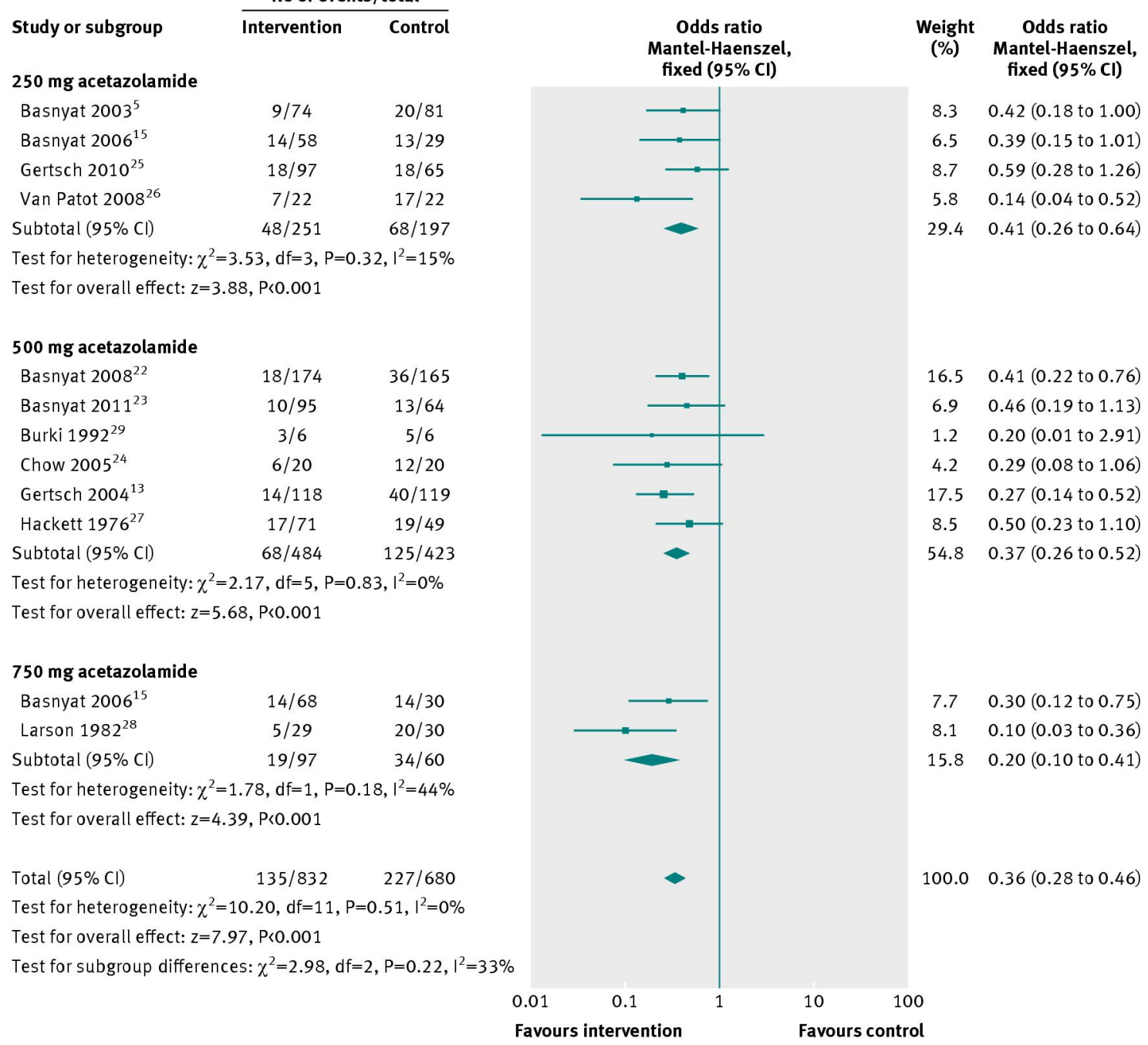

Fig 2 Forest plot for efficacy of acetazolamide by dose 


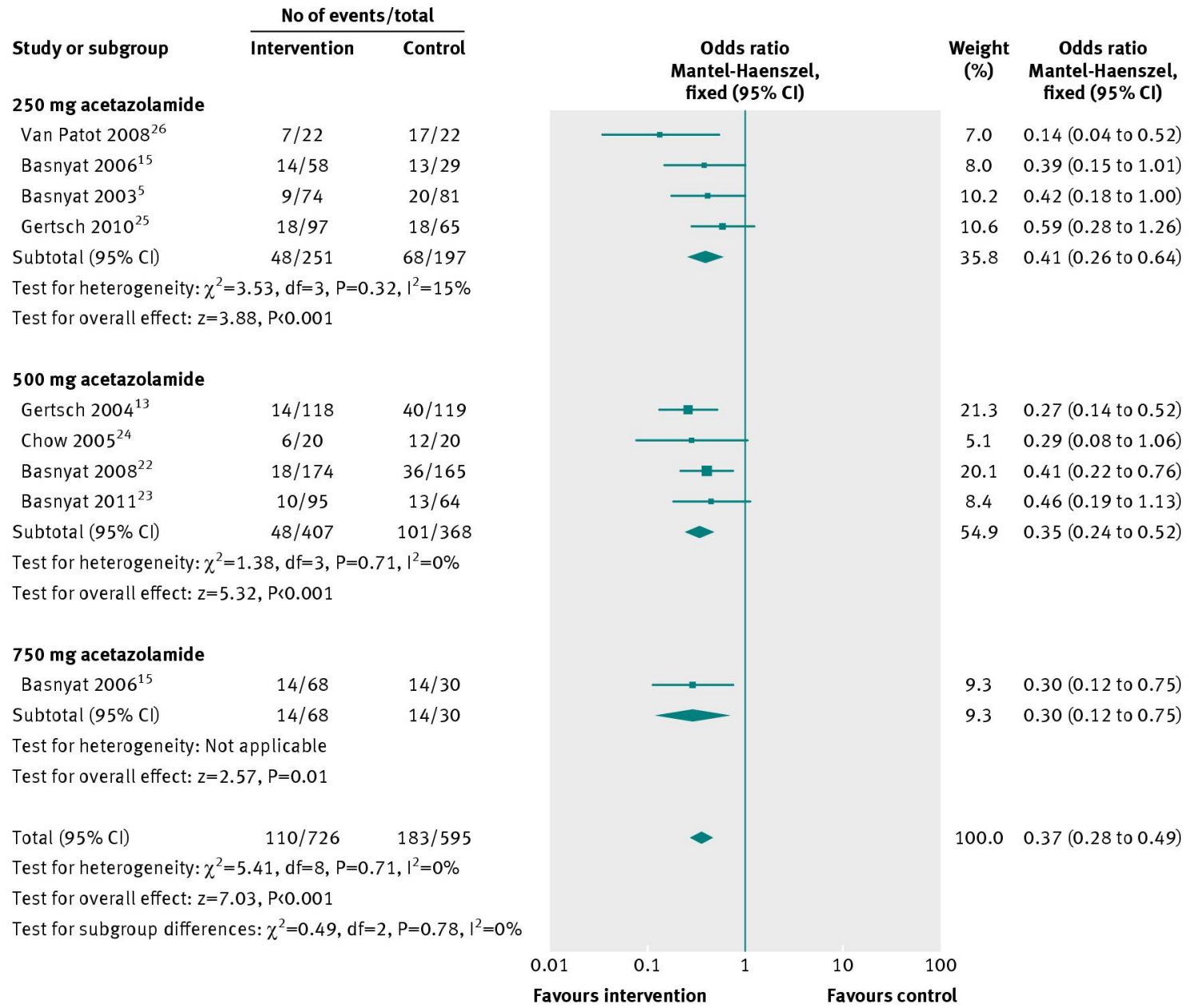

Fig 3 Forest plot for efficacy of acetazolamide by dose in sensitivity analysis 